\title{
Cigarettes, lung cancer, and coronary heart disease: the effects of inhalation and tar yield
}

\author{
TIM HIGENBOTTAM, ${ }^{2}$ MARTIN J SHIPLEY, ${ }^{2}$ AND GEOFFREY ROSE ${ }^{2}$ \\ From Papworth and Addenbrooke's Hospitals, ${ }^{1}$ Cambridge, and the Department of Medical Statistics and \\ Epidemiology, ${ }^{2}$ London School of Hygiene and Tropical Medicine, London WC1E 7HT
}

SUMMARY Ten-year mortality rates for lung cancer and coronary heart disease have been related to cigarette smoking habits in 17475 male civil servants aged 40-64 and in a sample of 8089 male British residents aged 35-69. Both diseases were more frequent in smokers. Lung cancer rates were higher overall for "non-inhalers", particularly in heavy smokers. Tar yield correlated with the risk of lung cancer in non-inhalers but less so in inhalers. Conversely, coronary deaths were more common among inhalers, and the effect of tar/nicotine yield (such as it was) was confined to inhalers. It appears that there are subtle interactions between the amount smoked, the tar/nicotine yield of the cigarette, and the style of smoking. Thus the effects of a change in cigarette characteristics are hard to predict, and they may be different for respiratory and cardiovascular disease.

Cigarette smoking is clearly associated with greatly enhanced risks of dying from coronary heart disease and lung cancer, ${ }^{1-4}$ but less is known as to how tobacco smoke either causes or promotes these diseases. It seems likely that lung cancer results from a direct effect of smoke on airways, ${ }^{5}$ while absorption from smoke of toxic constituents or metabolites contributes to coronary heart disease. ${ }^{\circ}$ Fuller understanding is hampered by the chemical complexity of tobacco smoke, whose composition, moreover, undergoes intricate changes during inhalation into the lungs: the site and degree of absorption of each constituent are determined not only by its solubility but also by the manner in which the smoke is inhaled..$^{78}$ Little is known of the capacity of the lungs to detoxify tobacco smoke.

Thus the health consequences of smoking depend not only on the amount smoked but also on the composition of the smoke and the manner of smoking. All of these factors interact, so that, for example, a reduction in tar and nicotine yield may sometimes lead to deeper inhalation. ${ }^{9}$ This suggests that at present we cannot predict the nett effect of changes in the characteristics of cigarettes.

To gain further insight into the relation of smoking to the development of lung cancer and coronary heart disease we have reviewed the mortality for these diseases among male civil servants in the Whitehall Study, ${ }^{10}$ and among men in a sample of the British population surveyed in the US/UK/Norwegian Migrants Study. ${ }^{11}$

\section{Methods}

A total of 18403 male civil servants in London, aged $40-64$, took part in the Whitehall Study.$^{10}$ The British Council and the diplomatic service (873 men) had a different system for grading employment, and these men have therefore been excluded from the present analysis since this required adjustment for employment grade. Each completed a self-administered questionnaire that included details of men's current daily cigarette consumption, their answers to the question, "Do you inhale?" and their usual brand of cigarette (from which tar yield was assessed, using an unpublished list supplied by the Tobacco Research Council). Adequate smoking data were available from 17475 men, among whom a total of 1657 deaths were identified over the next 10 years from the National Health Service Central Registry: 193 deaths were attributed to lung cancer (ICD $162 \cdot 1,8$ th revision) of which 143 occurred in cigarette smokers, and 704 to coronary heart disease (ICD 410-414), of which 407 were in cigarette smokers.

The data was cross-classified by age, employment grade, smoking factors (cigarettes a day, tar yield, and inhalation), and the analysis based on the method described by Nelder and Wedderburn. ${ }^{12}$ This allowed "effects" of different factors-for example, tar yield-together with their interactions to be assessed while controlling concomitant variation attributable to other factors - for example, age and 
Table 1 Number of men (\%) in each age and cigarette smoking category (Whitehall Study)

\begin{tabular}{|c|c|c|c|c|c|c|c|c|c|c|c|c|}
\hline \multirow[b]{2}{*}{ Age (years) } & \multirow{2}{*}{\multicolumn{2}{|c|}{ Non-smokers }} & \multirow{2}{*}{\multicolumn{2}{|c|}{ Ex-smokers }} & \multicolumn{4}{|c|}{ Smokers } & \multirow{2}{*}{\multicolumn{2}{|c|}{ Data incomplete }} & \multirow[b]{2}{*}{$\begin{array}{l}\text { Total } \\
\text { No }\end{array}$} & \multirow[b]{2}{*}{ (\%) } \\
\hline & & & & & $\begin{array}{l}\text { Inhaler } \\
\text { No }\end{array}$ & (\%) & $\begin{array}{l}\text { Non-in } \\
\text { No }\end{array}$ & $\begin{array}{l}\text { Thalers } \\
\text { (\%) }\end{array}$ & & & & \\
\hline $\begin{array}{l}40-49 \\
50-59 \\
60-64 \\
\text { All ages }\end{array}$ & $\begin{array}{r}1983 \\
1535 \\
359 \\
3877\end{array}$ & $\begin{array}{l}(27 \cdot 2) \\
(19 \cdot 4) \\
(15 \cdot 4) \\
(22 \cdot 1)\end{array}$ & $\begin{array}{r}2514 \\
2975 \\
888 \\
6377\end{array}$ & $\begin{array}{l}(34 \cdot 4) \\
(37 \cdot 6) \\
(38 \cdot 2) \\
(36 \cdot 4)\end{array}$ & $\begin{array}{r}2373 \\
2592 \\
761 \\
5726\end{array}$ & $\begin{array}{l}(32 \cdot 5) \\
(32 \cdot 8) \\
(32 \cdot 7) \\
(32 \cdot 7)\end{array}$ & $\begin{array}{r}410 \\
779 \\
306 \\
1495\end{array}$ & $\begin{array}{r}(5 \cdot 6) \\
(9.9) \\
(13.2) \\
(8.5)\end{array}$ & $\begin{array}{l}23 \\
21 \\
11 \\
55\end{array}$ & $\begin{array}{l}(0.3) \\
(0.3) \\
(0.5) \\
(0.3)\end{array}$ & $\begin{array}{r}7303 \\
7902 \\
2325 \\
17530\end{array}$ & $\begin{array}{c}(100 \cdot 0) \\
(100 \cdot 0) \\
(100 \cdot 0) \\
(100 \cdot 0)\end{array}$ \\
\hline
\end{tabular}

Table 2 Number of cigarette smokers according to daily consumption and tar yield showing inhalers and non-inhalers (\%), (Whitehall Study)

\begin{tabular}{|c|c|c|c|c|c|c|c|}
\hline \multirow{3}{*}{$\begin{array}{l}\text { Tar yield } \\
\text { (mg/cig) }\end{array}$} & \multirow{3}{*}{$\begin{array}{l}\text { Inhaling } \\
\text { status }\end{array}$} & \multicolumn{6}{|c|}{ Daily consumption of cigarettes } \\
\hline & & \multicolumn{2}{|l|}{$1-9$} & \multicolumn{2}{|c|}{$10-19$} & \multicolumn{2}{|l|}{$\geq 20$} \\
\hline & & No & (\%) & No & $(\%)$ & No & (\%) \\
\hline $\begin{array}{l}18-23 \\
24-32 \\
\geq 33\end{array}$ & $\begin{array}{l}\text { Inhaler } \\
\text { Non-inhaler } \\
\text { Inhaler } \\
\text { Non-inhaler } \\
\text { Inhaler } \\
\text { Non-inhaler }\end{array}$ & $\begin{array}{r}611 \\
356 \\
185 \\
146 \\
266 \\
67\end{array}$ & $\begin{array}{l}(63) \\
(37) \\
(56) \\
(44) \\
(80) \\
(20)\end{array}$ & $\begin{array}{r}1379 \\
322 \\
450 \\
95 \\
492 \\
74\end{array}$ & $\begin{array}{l}(81) \\
(19) \\
(83) \\
(17) \\
(87) \\
(13)\end{array}$ & $\begin{array}{r}1676 \\
296 \\
554 \\
115 \\
113 \\
24\end{array}$ & $\begin{array}{l}(85) \\
(15) \\
(83) \\
(17) \\
(82) \\
(18)\end{array}$ \\
\hline
\end{tabular}

employment grade. Mortality rates and $\chi^{2}$ tests for significance were calculated using the fitted models, and standardisation for controlled factors was achieved by weighting the estimated model's coefficients. All rates have been standardised for employment grade, which strongly influenced smoking habits (including inhalation and tar yield) as well as having an independent effect on mortality. All the models fitted included age and employment grade together with all their interactions so that the analysis was equivalent to performing a stratified analysis with the tests of significance computed using the Mantel-Haenszel procedure.

In 1964-5 as part of the US/UK/Norwegian Migrants Study ${ }^{11}$ we collected information on smoking habits from a sample of 8089 male UK residents aged 35-69; information on tar yield was unfortunately not recorded. Altogether 3707 were identified as smoking cigarettes only, and during the next 10 years 100 of these died from lung cancer and 247 from coronary heart disease.

\section{Results}

In table 1 men in the Whitehall Study are classified according to age and smoking habit. The proportion of cigarette smokers who said that they inhaled declined with age, from $85 \%$ at $40-49$ down to $71 \%$ at 60-64 years. Table 2 shows that reported inhaling varied with amount smoked and with tar yield: it was less common in those who smoked under 10 cigarettes daily, unless their cigarettes were in the highest tar range. Older smokers tended to prefer a higher tar yield (table 3 ).
Table 3 Numbers (\%) in each age group smoking cigarettes of different tar yields (Whitehall Study)

\begin{tabular}{llllllllll}
\hline & \multicolumn{7}{c}{ Tar yield (mg/cigarette) } \\
\cline { 2 - 8 } Age (years) & $18-23$ & $24-32$ & $\geqslant 33$ & & \multicolumn{3}{l}{ Total } \\
\hline $40-49$ & No & $(\%)$ & No & $(\%)$ & No & (\%) & No & $(\%)$ \\
$50-59$ & 1956 & $(70)$ & 503 & $(18)$ & 324 & $(12)$ & 2783 & $(100)$ \\
$60-64$ & 2130 & $(63)$ & 762 & $(23)$ & 479 & $(14)$ & 3371 & $(100)$ \\
& 554 & $(52)$ & 280 & $(26)$ & 233 & $(22)$ & 1067 & $(100)$ \\
\hline
\end{tabular}

Lung cancer mortality was strongly and very significantly related to amount smoked $(p<0.01)$ in both inhalers and "non-inhalers." This effect did not differ significantly between inhalers and non-inhalers. Overall, the mortality ratio for non-inhalers relative to inhalers was $1 \cdot 25(p=0 \cdot 3)$. In table 4 the rates (adjusted for age and employment grade) are analysed by cigarette consumption and tar yield. Among inhalers the effect of tar yield was not large. It was not seen at all in the heaviest smokers, and overall it fell short of conventional significance. Tar yield was more important among non-inhalers $(p=0.03)$, and thus the highest mortality from lung cancer was seen in non-inhalers who smoked high-tar cigarettes heavily.

Table 5 shows the lung cancer results from the migrants study. Among men smoking fewer than $\mathbf{2 0}$ cigarettes daily the rates are the same in inhalers and non-inhalers, whereas among heavier smokers they are higher in non-inhalers. This is the same pattern as in the Whitehall Study (last line of table 4).

Mortality from coronary heart disease in the Whitehall Study was higher in inhalers than non-inhalers (relative risk $1 \cdot 30, p=0.04$ ); but the 
Table 4 Ten-year lung cancer mortality per hundred (and number of deaths) standardised for age and employment grade, according to cigarette consumption and tar yield (Whitehall Study)

\begin{tabular}{|c|c|c|c|c|c|c|c|c|c|c|c|c|}
\hline \multirow[b]{2}{*}{$\operatorname{Tar}$ (mg/cig) } & \multicolumn{5}{|c|}{ Inhalers } & \multirow[b]{2}{*}{ No } & \multicolumn{5}{|c|}{ Non-inhalers } & \multirow[b]{2}{*}{ No } \\
\hline & $\begin{array}{l}1-9 / d \\
\text { Rate }\end{array}$ & No & $\begin{array}{l}10-19 / d \\
\text { Rate }\end{array}$ & No & $\begin{array}{l}\geqslant 20 / d \\
\text { Rate }\end{array}$ & & $\begin{array}{l}1-9 / d \\
\text { Rate }\end{array}$ & No & $\begin{array}{l}10-19 / d \\
\text { Rate }\end{array}$ & No & $\begin{array}{l}\geqslant 20 / d \\
\text { Rate }\end{array}$ & \\
\hline $\begin{array}{l}18-23 \\
24-32 \\
\geqslant 33 \\
\text { Total }\end{array}$ & $\begin{array}{l}0.39 \\
0.53 \\
1.62 \\
0.87\end{array}$ & $\begin{array}{r}(2) \\
(1) \\
(7) \\
(10)\end{array}$ & $\begin{array}{l}1.46 \\
1.55 \\
2.61 \\
1.79\end{array}$ & $\begin{array}{r}(19) \\
(8) \\
(20) \\
(47)\end{array}$ & $\begin{array}{l}2 \cdot 23 \\
2 \cdot 00 \\
1 \cdot 79 \\
2 \cdot 13\end{array}$ & $\begin{array}{r}(35) \\
(13) \\
(3) \\
(51)\end{array}$ & $\begin{array}{l}1.08 \\
0.00 \\
0.93 \\
0.75\end{array}$ & $\begin{array}{l}(4) \\
(0) \\
(1) \\
(5)\end{array}$ & $\begin{array}{l}1 \cdot 25 \\
1 \cdot 28 \\
4 \cdot 18 \\
1 \cdot 76\end{array}$ & $\begin{array}{r}(5) \\
(2) \\
(5) \\
(12)\end{array}$ & $\begin{array}{l}1 \cdot 71 \\
5 \cdot 81 \\
5.85 \\
3.01\end{array}$ & $\begin{array}{r}\text { (7) } \\
\text { (9) } \\
(2) \\
(18)\end{array}$ \\
\hline
\end{tabular}

Rate for life-long non-smokers of cigarettes $=0.20$ (6).

Table 5 Ten-year lung cancer mortality according to cigarette consumption (US/UK/Norwegian Migrants Study)

\begin{tabular}{|c|c|c|c|c|c|c|c|}
\hline & \multicolumn{3}{|l|}{ Inhalers } & \multicolumn{3}{|c|}{ Non-inhalers } & \multirow{2}{*}{$\begin{array}{l}\text { Incomplete } \\
\text { information }\end{array}$} \\
\hline & $\mid-9 / d$ & $10-19 / d$ & $\geqslant 20 / d$ & $1-9 / d$ & $10-19 / d$ & $>20 / d$ & \\
\hline $\begin{array}{l}\text { No in group } \\
\text { No of deaths } \\
\text { Mortality (\%) (age-adj) }\end{array}$ & $\begin{array}{l}365 \\
6 \\
1.64\end{array}$ & $\begin{array}{r}1442 \\
38 \\
2.69\end{array}$ & $\begin{array}{l}1283 \\
35 \\
3.05\end{array}$ & $\begin{array}{l}133 \\
3 \\
1 \cdot 64\end{array}$ & $\begin{array}{l}222 \\
8 \\
2 \cdot 70\end{array}$ & $\begin{array}{l}150 \\
9 \\
5 \cdot 07\end{array}$ & $\begin{array}{r}112 \\
1 \\
-\end{array}$ \\
\hline
\end{tabular}

Table 6 Ten-year coronary heart disease mortality per hundred (and number of deaths) standardised for age and employment grade, according to cigarette consumption and tar yield (Whitehall Study)

\begin{tabular}{|c|c|c|c|c|c|c|c|c|c|c|c|c|}
\hline \multirow[b]{2}{*}{ Tar (mg/cig) } & \multicolumn{6}{|c|}{ Inhalers } & \multicolumn{6}{|c|}{ Non-inhalers } \\
\hline & $\begin{array}{l}1-9 / d \\
\text { Rate }\end{array}$ & No & $\begin{array}{l}10-19 / d \\
\text { Rate }\end{array}$ & No & $\begin{array}{l}\geqslant 20 / d \\
\text { Rate }\end{array}$ & No & $\begin{array}{l}1-9 / d \\
\text { Rate }\end{array}$ & No & $\begin{array}{l}10-19 / d \\
\text { Rate }\end{array}$ & No & $\begin{array}{l}\geqslant 20 / d \\
\text { Rate }\end{array}$ & No \\
\hline $\begin{array}{l}18-23 \\
24-32 \\
\geq 33 \\
\text { Total }\end{array}$ & $\begin{array}{l}2 \cdot 68 \\
3 \cdot 81 \\
7 \cdot 42 \\
4 \cdot 29\end{array}$ & $\begin{array}{r}(14) \\
(7) \\
(23) \\
(44)\end{array}$ & $\begin{array}{l}5.63 \\
6.57 \\
6.47 \\
5.98\end{array}$ & $\begin{array}{c}(71) \\
(30) \\
(37) \\
(138)\end{array}$ & $\begin{array}{l}6.60 \\
6.23 \\
7.84 \\
6.56\end{array}$ & $\begin{array}{r}(101) \\
(36) \\
(10) \\
(147)\end{array}$ & $\begin{array}{l}3.94 \\
1.78 \\
5.08 \\
3.48\end{array}$ & $\begin{array}{r}(14) \\
(3) \\
(4) \\
(21)\end{array}$ & $\begin{array}{l}4.91 \\
9.03 \\
4.75 \\
5.73\end{array}$ & $\begin{array}{r}(17) \\
(10) \\
(4) \\
(31)\end{array}$ & $\begin{array}{l}6.05 \\
4.27 \\
0.00 \\
5 \cdot 18\end{array}$ & $\begin{array}{r}(20) \\
(6) \\
(0) \\
(26)\end{array}$ \\
\hline
\end{tabular}

Rate for life-long non-smokers of cigarettes $=2.75 \quad(70)$.

relative risk was reduced to $1 \cdot 16(p=0 \cdot 25)$ after adjusting for cigarette consumption and tar yield. Among inhalers the risk increased with the amount smoked $(p<0 \cdot 01)$, but this effect was less evident in non-inhalers $(p=0 \cdot 2)$. In table 6 the rates (adjusted for age and employment grade) are analysed by cigarette consumption and tar yield. (Nicotine yield, which may be more relevant to cardiovascular risk, was strongly correlated with tar yield). Among inhalers there was a tendency $(p=0.07)$ for the highest rates to be seen in those smoking cigarettes with the highest tar yield. Among non-inhalers there was no clear pattern. This trend is illustrated by the relative risks for inhalers $v$ non-inhalers at different levels of tar yield: 1.03 at $18-23 \mathrm{mg}, 1.19$ at $24-32$ $\mathrm{mg}$, and 1.91 in the highest tar group. This contrasts with what was found for lung cancer, where the effect of tar yield was stronger among non-inhalers than inhalers.

In the US/UK/Norwegian Migrants Study the general trend was similar, mortality from coronary heart disease being 1.25 times higher in inhalers than non-inhalers, after adjusting for age and daily cigarettes.

\section{Discussion}

In common with previous studies we found among cigarette smokers a much increased risk of lung cancer and fatal coronary heart disease. This risk was dose-related, except perhaps for coronary heart disease in non-inhalers. Our observations point also to a further dimension in the hazards associated with smoking - namely, the manner of smoking seems to relate differently to the risks of lung cancer on the one hand and of coronary heart disease on the other.

A greater risk of coronary heart disease among smokers who inhale is well recognised ${ }^{13}$ It is usually thought that the same should apply to the risk of lung cancer, and the results of Hammond's large American study ${ }^{1}$ supported this view. In the British doctors study, however, non-inhalers taken as a whole had a higher lung cancer mortality than inhalers. ${ }^{4}$ This effect arose from a considerable excess among non-inhalers smoking 25 or more cigarettes daily. Our results, from both the Whitehall Study and the US/UK/Norwegian Migrants Study (table 5), support the reality of this unexpected 
phenomenon. There is a consistency between these three studies, and perhaps the different finding in Hammond's study came from a failure to take simultaneous account of the amount smoked.

The occurrence of a risk of lung cancer in smokers who deny inhaling shows that rhe answers to this question are unreliable, since the excess risk must imply exposure of bronchi to smoke. In fact, Wald and his colleagues ${ }^{14}$ found that carboxyhaemoglobin levels in self-described non-inhalers were closer to those of inhalers than to those of non-smokers. Habits, moreover, may change, through disease, through a change in the type of cigarette, or for other reasons. The different associations with risk nevertheless show that the question on inhaling serves to discriminate two extremes of smoking behaviour. Other things being equal, the risk of coronary heart disease was higher in those reporting inhalation, whereas the risk of lung cancer was lower, at least for older and heavier smokers. The yield of tar affected the risk of lung cancer more among non-inhalers, whereas an effect of tar (or nicotine) on coronary heart disease was seen mainly among inhalers.

The average tar yield of cigarettes has been falling for many years. ${ }^{1516}$ This is due partly to manufacturing changes, partly to a growing preference for filtered cigarettes, and partly to the death of older smokers (who prefer a higher tar yield, table 3). Most cigarettes on sale today yield less tar than the lowest category in our initial survey (18-23 $\mathrm{mg}$ ), which was conducted 10-12 years ago. Differences within the much lower current range may not have the same influence on disease as those which we observed between the higher levels. The case for advocating a reduction from middle to low yield of tar rests on extrapolation from the differences observed between smokers of high (or very high) and middle yields. Our findings (table 4) give little support for such extrapolation. Further analysis of smokers in the lowest tar category (18-23 mg) showed that although cigarette consumption was still a strong risk factor for both lung cancer and coronary heart disease $(p<0.01)$, there were no differences between inhalers and non-inhalers for these causes of death.

The results for coronary heart disease imply that the relationship to smoking depends on the absorption of smoke products. Unfortunately, it is not known which particular factor is to blame. Full inhalation much enhances the alveolar absorption of both soluble and less soluble gaseous components, including nicotine. ${ }^{9}$

The results for lung cancer are less readily explained. Possibly during full inhalation the smoker passes a concentrated bolus of smoke swiftly past the tumorigenic zone: by the time he exhales, the gases have been largely absorbed and most of the particulate matter has been deposited in the depths of the lungs, whence it is cleared by macrophages or by ciliary action. The situation is different for the non-inhaler - that is, the unwitting inhaler. If his inhalation occurs later in inspiration then the concentration of smoke in the "dead space" air might be higher than for the bolus inhaler: and it is this dead space fraction of the tidal volume that remains longest in contact with the main bronchi. Alternatively, his inhalation may be spread more evenly throughout inspiration with the same effect.

Regardless of the explanation of the phenomenon, the important lesson is that the risks of smoking depend not only on what is smoked but on how it is smoked. The interactions are subtle, incompletely understood, and hence not predictable. Smokers changing to a product yielding less tar and nicotine may tend to compensate for the fall in nicotine by inhaling more deeply. ${ }^{9}$ This might be additionally beneficial for the lung cancer risk, but it could possibly increase the larger danger of fatal coronary heart disease. More circumspection is needed in advocating such a change, with more research into its long-term influence on the absorption of smoke products.

We are grateful to Mr P N Lee for helpful comments. One of us (MJS) was supported in part by a grant from the British Heart Foundation.

Reprints from Professor Geoffrey Rose, Department of Medical Statistics and Epidemiology, London School of Hygiene and Tropical Medicine, Keppel Street, London WC1E 7HT.

\section{References}

${ }^{1}$ Hammond EC. Smoking in relation to the death rates of one million men and women. Natl Cancer Inst Monogr 19: 1966: 127-204.

${ }^{2}$ Hammond EC, Garfinkel L. Coronary heart disease, stroke and aortic aneurysm: factors in the etiology. Arch Environ Health 1969; 19: 167-82.

${ }^{3}$ Weir JM, Dunn JE. Smoking and mortality: a prospective study. Cancer 1970; 25: 105-12.

'Doll R, Peto R. Mortality in relation to smoking: 20 years' observations on male British doctors. Br Med J 1976; ii: 1525-36.

'US Public Health Service. The health consequences of smoking. Supplement to Public Health Service Publication No 1696. Washington, DC: US Government Printing Office, 1969.

- Wald N, Howard S, Smith PG, Kjeldsen K. Association between atherosclerotic diseases and carboxyhaemoglobin levels in tobacco smokers. $\mathrm{Br} \mathrm{Med}$ J 1973; i: 761-5. 
${ }^{7}$ Dalhamn T, Edford ML, Rylander R. Retention of cigarette smokers components in human lungs. Arch Environ Health 1968; 18: 746-8.

${ }^{8}$ Rawbone RG, Murphy K, Tate ME, Kane SJ. The analysis of smoking parameters: inhalation and absorption of tobacco smoke in studies of human smoking behaviour. In: Thornton RE, ed. Smoking behaviour. Edinburgh: Churchill Livingstone, 1978; 171-94.

${ }^{9}$ Russell MAH, Jarvis M, Iyer R, Feyerabend C. Relation of nicotine yield of cigarettes to blood nicotine concentration in smokers. $\mathrm{Br} \mathrm{Med} J$ 1980; 280: 972-6.

${ }^{10}$ Reid DD, Brett GZ, Hamilton PJS, Jarrett RJ, Keen H, Rose G. Cardiorespiratory disease and diabetes among middle-aged male civil servants. Lancet 1974; i, 469-73.

${ }^{11}$ Reid DD. Studies of disease among migrants and native populations in Great Britain, Norway and the United States. 1. Background and design. Natl Cancer Inst Monogr 19: 1966: 287-99.
${ }^{12}$ Nelder JA, Wedderburn RWM. Generalised linear models. Journal of the Royal Statistical Society A. 1972; 135: 370-84.

${ }^{13}$ Reid DD, Hamilton PJS, McCartney P, Rose G, Jarrett $\mathrm{RJ}, \mathrm{Keen} \mathrm{H}$. Smoking and other risk factors for coronary heart disease in British civil servants. Lancet 1976; ii: 979-84.

${ }^{14}$ Wald N, Idle M, Bailey A. Carboxyhaemoglobin levels and inhaling habits in cigarette smokers. Thorax 1978; 33: 201-6.

${ }^{15}$ Tobacco Research Council. Statistics of smoking in the United Kingdom. Research Paper No 1. 7th ed. Lee PN, ed. London: Tobacco Research Council, 1976.

${ }^{16}$ Capell PJ. Trends in cigarette smoking in the United Kingdom. Health Trends 1978; 10: 49-54. 